\title{
Introduction to the Special Issue on the 2014 Peter J. Buckley and Mark Casson AIB Dissertation Award
}

\author{
Peter Buckley, University of Leeds, UK
}

\section{AIB Dissertation Award Competition}

Those of you who were privileged to be at the AIB Annual Conference session in Vancouver when the five finalists of the Peter J. Buckley and Mark Casson AIB Dissertation Award presented their dissertations in 12 minutes each will be unsurprised to read that this was an excellent year for international business doctorates. Neither will you be surprised that this was an incredibly difficult competition to judge. You will be aware that choosing among the five finalists was an almost impossible task, but prior to that, these five had to be selected from a total of 31 submissions, all of which were rated and ranked by an incredibly diligent and knowledgeable committee - Rebecca Piekkari, Anu Phene and Mark Casson, chaired by myself.

The five finalists were:

"Trajectory of Innovation in Emerging Industries: Evidence from the Global Wind Power Industry" by Snehal Suyash Awate, Indian School of Business (Ph.D. awarded by Temple University)

"The Organizational Design of Offshoring" by Marcus M Larsen (Ph.D. awarded by Copenhagen Business School)

"Pro-internationalisation Policy and Outward Foreign Direct Investment" by Miguel Matos Torres (Ph.D. awarded by Universidade de Aveiro)

"Multinational Enterprises and Performance: Three Essays at the Interface between International Business and Strategic Management" by Lars Matysiak (Ph.D. awarded by Justus Liebig University Giessen)

"Foreign Acquisitions by Indian Multinational Enterprises: A Test of Internationalisation Frameworks" by Surender Munjal (Ph.D. awarded by University of Leeds)

The finalists represented both a broad geographical spread (North America and Europe with strong Indian characteristics) and a diverse set of topics. The dissertations covered both qualitative and quantitative techniques and ranged across international strategy, industrial studies and government policy.

The breadth of the field of international business is illustrated not only by the five finalists but also in the scope of subjects covered in the submissions - and gratifyingly, in the range of institutions, nationality of applicants, supervisors and host countries covered by these applicants.

\section{What Do We Learn from the Competition?}

First, that international business is a vibrant field, attracting high quality students and producing high quality doctorates. Second, that the scope of the subject is broadening. The rise of emerging economies is mirrored in the applicant institutions, students and supervisors. There is no question that the rise of China, India and other "new entrants" (or re-entrants) into global competition has provided important subject material for dissertations - notably, inward and outward FDI from these economies, new multinational firms and strategies and a renewed focus on "context." The questioning of old theories and empirical results that has occurred is healthy for our field. Third, there is an improvement in research techniques right across our field. Both quantitative and qualitative methodologies are undergoing a renaissance and, one hopes, this will soon be reflected in our top journals, notoriously conservative as they are. Fourth, new sources of empirical evidence are emerging. Where data are unavailable and/or unreliable as, for example, the case of Chinese outward FDI and Chinese multinationals, new sources and techniques are employed to provide surrogate means of measurement. Many inventive techniques were seen in the submissions. The imaginative creation of data - both secondary and primary - is a feature of the "new international business."

It is encouraging to see doctoral researchers who regard themselves as pioneers - not adding footnotes to well-worn pieces but venturing out into the new creative fields in theory, technique and empirical work. This is the objective towards which the Buckley and Casson Award exists. Long may it continue.

I should end by thanking Henley Business School, University of Reading, and the Centre for International Business, University of Leeds, for sponsoring the dissertation award, the AIB Secretariat (and particularly Tunga Kiyak) for organising the event and the late Alan Rugman, who was a prime mover in setting up the Buckley and Casson Award.

Peter J Buckley, OBE, FBA, is Professor of International Business, Founder Director of the Centre for International Business, University of Leeds (CIBUL). Founder Director of the Business Confucius Institute at the University of Leeds and Cheung Kong Scholar Chair Professor in the University of International Business and Economics (UIBE), Beijing. President of the Academy of International Business 2002-04. 